\title{
Ecophysiology of Penicillium expansum and patulin production in synthetic and olive-based media
}

\author{
Mohamed Hamdi a, b, Hend Bejaoui ${ }^{\text {b }}$, Jorge Sá-Morais a , Paula Rodrigues ${ }^{\mathrm{a}, *}$ \\ a Centro de Investigação de Montanha (CIMO), ESA, Instituto Politécnico de Bragança, Campus de Santa Apolónia, 5300-253 Bragança, Portugal \\ ${ }^{\mathrm{b}}$ Institute Supérieur de Biotechnologie de Monastir, Université de Monastir, Tunisia
}

\section{A R T I C L E I N F O}

\section{Article history:}

Received 15 March 2019

Received in revised form

18 July 2019

Accepted 13 August 2019

Available online 21 August 2019

Corresponding Editor: Angel Medina

\section{Keywords:}

Food safety

Moulds

Mycotoxins

Olives

Storage

\begin{abstract}
A B S T R A C T
Olives and their derivatives, in particular olive oil, represent one of the most significant agricultural products in the Mediterranean basin. Storage under inadequate conditions poses serious problems concerning fungal contamination, with consequent defects and potential mycotoxin production in olives and olive oils. Penicillium expansum represents one of the most significant postharvest pathogens in several fruits, including olives. Not only it causes blue mold but also is one of the most relevant patulin producing species of the genus Penicillium.

The aim of this research was to evaluate the ecophysiological conditions governing growth and PAT production by $P$. expansum strains previously isolated from Tunisian olives. For this purpose, four $P$. expansum isolates were tested in a synthetic medium (Czapek Yeast Autolysate, CYA) and in olivebased medium $(\mathrm{OM})$ for their ability to grow and produce PAT under different temperatures $\left(4^{\circ} \mathrm{C}\right.$, $15{ }^{\circ} \mathrm{C}$ and $25^{\circ} \mathrm{C}$ ) for 10 and $20 \mathrm{~d}$. The mycotoxin was analysed by HPLC-UV.

Results showed that all isolates were able to grow on tested media at different temperatures. Different PAT production profiles were found, showing that at $25^{\circ} \mathrm{C}$ P. expansum isolates were able to produce PAT on CYA and OM medium. At $15^{\circ} \mathrm{C}$ the production of PAT was only detected on CYA medium, while no PAT production was detected at $4{ }^{\circ} \mathrm{C}$ for the two media.
\end{abstract}

๑) 2019 British Mycological Society. Published by Elsevier Ltd. All rights reserved.

\section{Introduction}

Olives and their derivatives, in particular olive oil, represent one of the most significant agricultural products in the Mediterranean basin. Tunisia is considered the fourth largest producer of olive oil in the world (Abdelhamid et al., 2013). Tunisian olive oil production has an important position in the olive oil market; it exports about $75 \%$ of its production and is considered as the second largest exporter after the European Union with an average of 115,000 tons per y over the last five years $(\mathrm{ONH}, 2015)$. In Tunisia, the olive sector contributes directly or indirectly to more than one million people and provides 34 million d of work per $\mathrm{y}$, which is equivalent to more than 20 \% of agricultural employment (Gharbi et al., 2015).

Olives are often stored for a long time under conditions that promote the growth of molds, such as prolonged contact with the ground, in bags of jute and in little ventilated places with high relative humidity. Contamination of olive fruits by hazardous

\footnotetext{
* Corresponding author.

E-mail address: prodrigues@ipb.pt (P. Rodrigues).
}

microorganisms may also occur through insect pest infestation (AlAmeiri et al., 2015). Such conditions favor a moldy taste and appearance and thus reduce the acceptable quality of olives and olive oils (Heperkan et al., 2006). Inappropriate storage or fermentation conditions favor the proliferation of hazardous fungi such as Penicillium sp. (Heperkan et al., 2009, Heperkan, 2013).

According to Roussos et al. (2006), olives can support the growth of mold and mycotoxins production. Many fungal strains, in particular from Aspergillus, Penicillium and Alternaria species, are able to grow on olives and produce several mycotoxins, and these genera have been reported as the dominant fungi on olives and olive products (El Adlouni et al., 2006; Roussos et al., 2006; Bavaro et al., 2017). Mycotoxin contamination of olives has also been studied, mostly for aflatoxins, ochratoxin A and citrinin (Leontopoulos et al., 2003; Ghitakou et al., 2006; Heperkan et al., 2009). Still, compared with other agricultural commodities, studies concerning contamination of olives with toxigenic fungi and the ability of these fungi to produce mycotoxins in this matrix are scarce.

Several Penicillium species were found on olives, including P. expansum, Penicillium citrinum and Penicillium crustosum (Arici, 2000; Heperkan et al., 2006, 2009; Bavaro et al., 2017). 
P. expansum is a wound parasite fungus that enters fruits via injuries potentially caused by inadequate conditions before harvest or by rough handling, harvesting, and transport (Sanderson and Spotts, 1995). It is one of the best-known and most studied molds of the genus Penicillium, occurring frequently at fruit harvest or postharvest stages (Andersen et al., 2004). P. expansum is known to contaminate a wide range of foods including apples, pears, cherries, walnuts, pecans, olives, hazelnuts, and acorns (Filtenborg et al., 1996; Zouaoui et al., 2015). It's defined as an important producer of PAT and citrinin, and is the major mycotoxin menace in apples and apple-derived products such as apple juice, purée, jam and cider (Frisvad and Samson, 2004). Studies of this species have been generally devoted PAT contamination and production in apple, apple juice, pears and cereals. However, only few studies report the contamination of olives with this species (Arici, 2000; Bavaro et al., 2017). To our knowledge, no studies have been developed on the detection of PAT in olives or other olive-derived products.

PAT is considered to have potential mutagenic, carcinogenic and embryotoxic effects on humans (Puel et al., 2010). The World Health Organization and the Food and Agriculture Organization have set a Maximum Tolerable Daily Intake for PAT of $0.4 \mu \mathrm{g} / \mathrm{kg}$ body weight/ day (Leggott and Shephard, 2001). The European Commission has set limits of allowable PAT content in various foodstuffs: $50 \mu \mathrm{g} / \mathrm{L}$ in fruit juices and spirit drinks, $25 \mu \mathrm{g} / \mathrm{L}$ in solid apple products and $10 \mu \mathrm{g} / \mathrm{L}$ in infant food (EC, 2006).

It is thus necessary to acknowledge the importance of $P$. expansum in olives and to determine its ability to produce PAT in olive-based substrates under different conditions, by determining the ecophysiological conditions governing PAT production by the fungus. This knowledge is of major importance to make a risk assessment and to develop preventive measures especially during storage.

The objectives of this work were to study the effect of temperature and matrix on $P$. expansum strains isolated from Tunisian olives in terms of growth and PAT production.

\section{Materials and methods}

\subsection{Fungal isolates}

Four PAT producing strains of Penicilium expansum were used in this study. From these, three were selected from a group of 28 isolates previously obtained from olives intended for oil production from Tunisian olive groves. The PAT producing strain P. expansum MUM 10.175 (further referred to as MUM), originating from a contaminated culture of Botrytis cinerea and obtained from Micoteca da Universidade do Minho (MUM), Braga, Portugal, was used as positive control.

All isolates were maintained in $20 \%$ glycerol at $-20{ }^{\circ} \mathrm{C}$ and grown on Malt Extract Agar (MEA: Malt $20 \mathrm{~g} / \mathrm{L}$, Glucose $20 \mathrm{~g} / \mathrm{L}$, Peptone $1 \mathrm{~g} / \mathrm{L}$, Agar $20 \mathrm{~g} / \mathrm{L}$; autoclaved for $15 \mathrm{~min}$ at $121^{\circ} \mathrm{C}$ ) in the dark for $7 \mathrm{~d}$ at $25^{\circ} \mathrm{C}$ whenever needed for further studies.

\subsection{Identification of fungal isolates}

All fungal isolates were subjected to a preliminary morphological identification to the genus level following general taxonomic guides (Samson et al., 2004; Pitt and Hocking, 2009). From 7 d old cultures on MEA, a loop full of spores was suspended in $500 \mu \mathrm{L}$ of $0.2 \%$ agar with $0.05 \%$ Tween 80 , and this suspension was used for three-point inoculations on 9-cm diameter Petri dishes containing MEA and Czapek Yeast Extract Autolysate (CYA) Agar medium (sucrose $30 \mathrm{~g} / \mathrm{L}$; yeast extract $5 \mathrm{~g} / \mathrm{L}$; dipotassium hydrogen phosphate $1 \mathrm{~g} / \mathrm{L}$; sodium nitrate $0.3 \mathrm{~g} / \mathrm{L}$; potassium chloride $0.05 \mathrm{~g} / \mathrm{L}$; magnesium sulphate $0.05 \mathrm{~g} / \mathrm{L}$; ferrous sulphate $0.001 \mathrm{~g} / \mathrm{L}$; zinc sulphate $0.001 \mathrm{~g} / \mathrm{L}$; copper sulphate $0.0005 \mathrm{~g} / \mathrm{L}$; agar $15 \mathrm{~g} / \mathrm{L}$ ), as described in Rodrigues et al. (2013).

Cultures were incubated in the dark at $25^{\circ} \mathrm{C}$ and were analyzed after $7 \mathrm{~d}$ of incubation for the following characters: colony growth and texture, obverse and reverse colony color, diffusible pigments and exudate production and microscopic characteristics, with the help of taxonomic guides of the genus Penicillium (Frisvad and Samson, 2004).

From the 28 olive-native isolates, four were morphologically identified as $P$. expansum. Morphological identification was confirmed by molecular analysis. Genomic DNA was obtained following the methodology described by Rodrigues et al. (2009). The universal primers ITS1-F (5' CTTGGTCATTTAGAGGAAGTAA-3') and ITS4 (5'-TCCTCCGCTTATTGATATGC- $3^{\prime}$ ) (White et al., 1990; Gardes and Bruns, 1993), which amplify a 600 bp segment of the ITS1/5.8S/ITS2 region of the rRNA gene, were used for sequencing purposes. PCR amplifications were performed as described by Rodrigues et al. (2011). PCR products were purified with the commercial GF-1 PCR cleanup kit (Vivantis), according to the instructions of the manufacturer.

Sequence analysis was performed in both directions, on an $\mathrm{ABI}$ 3730xl DNA Analyzer (Applied Biosystems). Sequence comparison was performed using the Basic Local Alignment Search Tool (BLAST) in GenBank (http://blast.ncbi.nlm.nih.gov/Blast.cgi) and the Pairwise Sequence Alignment in the MycoBank Database (http://www mycobank.org/defaultinfo.aspx?Page=Home).

\subsection{Screening of patulin producing ability by P. expansum isolates}

The four P. expansum isolates were tested for PAT production on CYA. Fungi were inoculated by three-point inoculation on $9 \mathrm{~cm}$ Petri dishes containing $20 \mathrm{~mL}$ of CYA and incubated for $7 \mathrm{~d}$ in the dark at $25^{\circ} \mathrm{C}$. After incubation, the methodology of Bragulat et al. (2001) was employed by removing 3 agar plugs from one colony, placed into a $4 \mathrm{~mL}$ ambar vial, and $1 \mathrm{~mL}$ of methanol was added. After $60 \mathrm{~min}$, the extract was filtered by $0.2 \mu \mathrm{m}$ syringe filters into $1.8 \mathrm{~mL}$ HPLC vials.

PAT detection was performed on an HPLC system equipped with: an autosampler (HTA, HT800L); a pump (Varian 9010); a reverse phase C18 column (Supelco Kromasil, $4.6 \times 150 \mathrm{~mm}, 5 \mu \mathrm{m}$ ), fitted with a precolumn with the same stationary phase; and an ultra-violet detector with Diode-Array Detection (PDA) set to $276 \mathrm{~nm}$ wavelength (Varian, Prostar; 330). Oven temperature was set to $30^{\circ} \mathrm{C}$. Star chromatography Workstation version 6.41 software was used for instrument control and data processing. The mobile phase was composed of methanol and water at 10:90 (v/v) with a flow rate of $0.8 \mathrm{~mL} / \mathrm{min}$. The injection volume was $10 \mu \mathrm{L}$ and the run was $20 \mathrm{~min}$. The detection of patulin was done by comparison with the standard.

Among the four isolates tested, three were detected as PAT producers. The three PAT producing isolates of $P$. expansum TUN20, TUN22 and TUN23 (further referred to as TUN strains) were selected for further ecophysiological studies in terms of growth and PAT production.

\subsection{Ecophysiology of Penicillium expansum growth and PAT production}

\subsubsection{Media preparation}

For the ecophysiological studies, two different culture media were used: CYA, used as control; and olive-based medium (OM), used as a model to reflect the olive matrix. OM was prepared as follows: Tunisian olives previously collected were rinsed with bleach for $5 \mathrm{~min}$, washed twice with distilled water, deboned and ground with a blender at low speed for $5 \mathrm{~s}$ to obtain a homogeneous 
paste. The paste $\mathrm{pH}$ was 5.3 , and water activity was 0.98 (measured with a water activity meter $4 \mathrm{TE}, \mathrm{AQUA} \mathrm{LAB}$ ). Olive based-medium was prepared by mixing one part of olive paste with 6 parts of water (p:v). $1.5 \%$ agar were added and the medium was autoclaved for $15 \mathrm{~min}$ at $121^{\circ} \mathrm{C}$. Both media were plated in $9 \mathrm{~cm}$ Petri dishes.

\subsubsection{Inoculation, incubation and measurement of growth}

Spore suspensions of each $P$. expansum strain were obtained by adding $1 \mathrm{~mL}$ of sterilized water with $0.05 \%$ Tween 80 to a $7 \mathrm{~d}$-old culture and by scrubbing the spores. Spore suspensions were adjusted to $10^{6}$ spores/mL by counting cells with the aid of a Neubauer counting chamber. $10 \mu \mathrm{L}$ of each suspension were transferred by central-point inoculation to Petri dishes containing $20 \mathrm{~mL}$ of each medium (CYA and OM). Sets of three Petri dishes were incubated at 3 different temperatures: $25^{\circ} \mathrm{C}, 15^{\circ} \mathrm{C}$ and $4{ }^{\circ} \mathrm{C}$ for $20 \mathrm{~d}$. Petri dishes without fungi (medium only) were used as negative control.

Fungal growth was observed daily and measurement of fungal colonies diameter (in $\mathrm{cm}$ ) was made after 3, 5, 8, 10, 15 and $20 \mathrm{~d}$ of incubation. The procedure was done in triplicate.

\subsubsection{Quantification of PAT production}

2.4.3.1. Preparation of PAT standard solutions. The stock standard solution of PAT was dissolved in ethyl acetate at a concentration of $1 \mathrm{mg} / \mathrm{mL}$. This stock solution was diluted with methanol to obtain working solutions as needed. Concentration of PAT standards was confirmed by measuring the UV absorbance at $276 \mathrm{~nm}$ and calculated by using the molar extinction coefficient $\varepsilon$ of $14,600 \mathrm{~L} / \mathrm{mol} / \mathrm{cm}$ (AOAC, 2000). The prepared solutions were stored at $4{ }^{\circ} \mathrm{C}$.

2.4.3.2. Method validation. HPLC analysis using methanol as solvent was selected as the analytical method for PAT detection and quantification. Linearity, limit of detection (LOD) and limit of quantification (LOQ) were determined following the analytical method validation guidelines described by Taverniers et al. (2004). Linearity was demonstrated by using 7 standard solutions in methanol with concentrations ranging from $0.2 \mu \mathrm{g} / \mathrm{mL}$ to $125 \mu \mathrm{g} /$ $\mathrm{mL}$. LOD and LOQ were calculated according to the following equations: $\mathrm{LOD}=\mathrm{y}_{0}+3 \times \mathrm{S}_{\mathrm{y} / \mathrm{x}}$ and $\mathrm{LOQ}=\mathrm{y}_{0}+10 \times \mathrm{S}_{\mathrm{y} / \mathrm{x}}$, where $Y_{0}$ is the intercept of the regression line obtained from the calibration curve, and $S_{y / x}$ is the standard error of the slope. OTA was quantified by gram of agar, taking into consideration the weight of the agar plugs used for extraction.

Recovery from the two culture media was determined as follows: $50 \mu \mathrm{g} / \mathrm{g}$ of PAT were spiked into $1 \mathrm{~g}$ of each medium (CYA and $\mathrm{OM}$ ) and kept for $30 \mathrm{~min}$ in the dark. Then $1 \mathrm{~mL}$ of methanol was added and PAT extraction occurred for $60 \mathrm{~min}$, with vortexing every $15 \mathrm{~min}$. The extract was filtered through PVDF $0.2 \mu \mathrm{m}$ syringe filters and stored at $4{ }^{\circ} \mathrm{C}$ until HPLC analysis. The procedure was done in triplicate. Recovery rate (\%) was calculated by the ratio of recovered PAT concentration relative to the known spiked concentration. Precision was calculated in terms of intra-day repeatability (RSDr; $\mathrm{n}=3$ ), and is given by the corresponding relative standard deviation.

2.4.3.3. PAT extraction from fungal cultures. After $10 \mathrm{~d}$ and $20 \mathrm{~d}$ of incubation, all cultures were submitted to PAT extraction. Three agar plugs were removed from the inner, middle and outer areas of the colony, weighted and extracted with methanol as previously described. Quantification of PAT was performed by measuring area's peak at PAT retention time and plotting against the calibration curve. PAT was quantified by gram of agar, taking into consideration the weight of the agar plugs used for extraction.

\subsection{Statistical analysis}

Statistical analysis was performed using IBM ${ }^{\circledR}$ SPSS ${ }^{\circledR}$ Statistics v.22.0 software (Armonk, NY: IBM Corp.). The variables under study (growth and PAT concentration) did not show a normal distribution, therefore the non-parametric statistical Kruskal-Wallis test was used for comparison of means, and post-hoc analyses were performed with corresponding U-Mann Whitney test. Correlation between fungal growth and PAT production was studied by analyzing Spearman correlation index. In all cases, statistical significance was established at $p \leq 0.05$.

\section{Results and discussion}

This study was carried out on three strains of $P$. expansum previously isolated from Tunisian groves (TUN strains), using a culture collection strain (MUM 10.175) as non-native control.

$P$. expansum has frequently been defined as an important contaminant and producer of PAT and citrinin in several fruits, mostly apples and pears (Gimeno and Martins, 1983; Laidou et al., 2001; Martins et al., 2002; Frisvad and Samson, 2004; Baert et al., 2007a; Morales et al., 2007a, 2007b; 2007c, 2008; 2010; Abramson et al., 2009). In our study, among a group of 28 fungal isolates, four ( $14 \%$ ) were identified as $P$. expansum, of which three were able to produce patulin. These results are in agreement with those from another recent study on molds associated with fermented black table olives from Italy and Turkey (Bavaro et al., 2017), where $10 \%$ of the isolated strains belonged to this species. According to these results, $P$. expansum seems to be an important contaminant of olives.

Few studies of $P$. expansum have been conducted to characterize the growth and the toxigenic conditions of this species, despite its large implication in foodstuff contamination. The understanding of ecophysiology of $P$. expansum under controlled experimental conditions may help to understand its behavior under natural storage conditions and forecast its potential risks on the fruit and consumer's health.

For this, $P$. expansum strains were tested on a synthetic medium (CYA) and on olive based-medium (OM) and were submitted to adequate $\left(4^{\circ} \mathrm{C}\right)$ and abusive $\left(15^{\circ} \mathrm{C}\right.$ and $\left.25^{\circ} \mathrm{C}\right)$ storage temperatures. Water activity was not included as a variable since olives don't suffer significant aw variations throughout storage. Atmosphere composition was also not included since previous research on apples has shown that atmosphere composition had no effect on P. expansum growth and patulin production (Baert et al., 2007b).

\subsection{Influence of matrix and temperature on fungal growth}

In terms of fungal growth (colony diameter), the Kruskal-Wallis test did not reveal significant differences between the three olivenative strains (TUN) analyzed ( $\mathrm{p}>0.05$ ), but significant differences were observed between the MUM strain and the TUN strains $(p<0.05)$. Therefore, results for growth are further represented separately for MUM (three replicas) and for TUN (three strains $\mathrm{X}$ three replicas).

The results of fungal growth throughout $20 \mathrm{~d}$ of incubation in both media for all temperatures tested are shown in Fig. 1. Fig. 2 compares the fungal growth, in mm/day, of MUM and TUN strains. For all the tested conditions, the growth curves based on colony diameters were typical of a linear fungal growth until the moment when fungal growth was limited by the Petri dish dimension (single colony in $9 \mathrm{~cm}$ ). In such cases, growth curves lose their linear appearance just after reaching the limiting diameter of $9 \mathrm{~cm}$. 

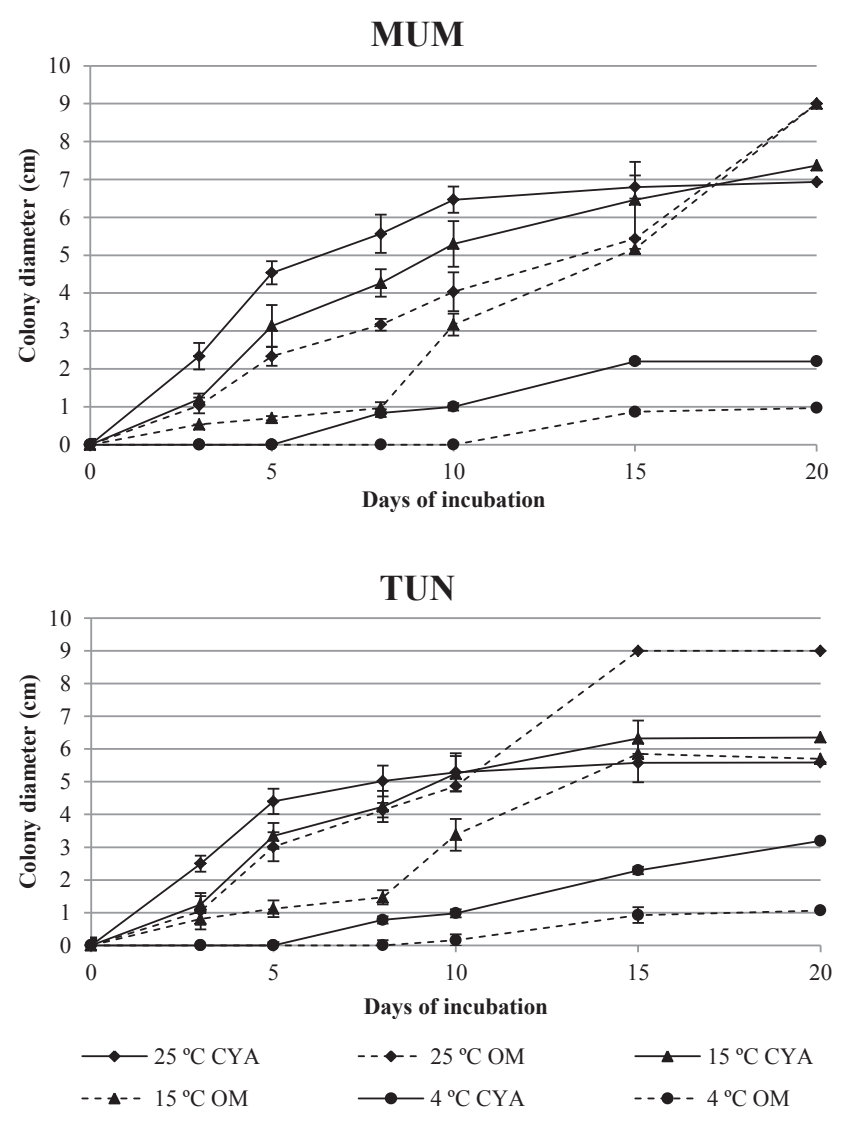

Fig. 1. Growth curves of Penicillium expansum strains. Top: MUM ( $n=3)$; Bottom: TUN ( $\mathrm{n}=9$ ), at $4{ }^{\circ} \mathrm{C}, 15^{\circ} \mathrm{C}$ and $25^{\circ} \mathrm{C}$ in $\mathrm{CYA}$ and $\mathrm{OM}$.

The influence of the matrix on $P$. expansum growth was studied by inoculating the strains on two different media: CYA, a synthetic standardized medium generally used to study fungal growth, was used as positive control; and OM, an olive-based medium, was used as a model system to substitute the use of integral olives. Culture media prepared from selected food products have been generally considered a good approximation to the growth and toxin production patterns contained in natural substrates (Pardo et al., 2005), and have been frequently used as model systems in similar ecophysiological studies (e.g. Marín et al., 2006; Gil-Serna et al., 2014; Rodríguez et al., 2015; Vipotnik et al., 2017).

In the present study, the matrix had a significant influence on the growth profile throughout time. Fungal growth was better on

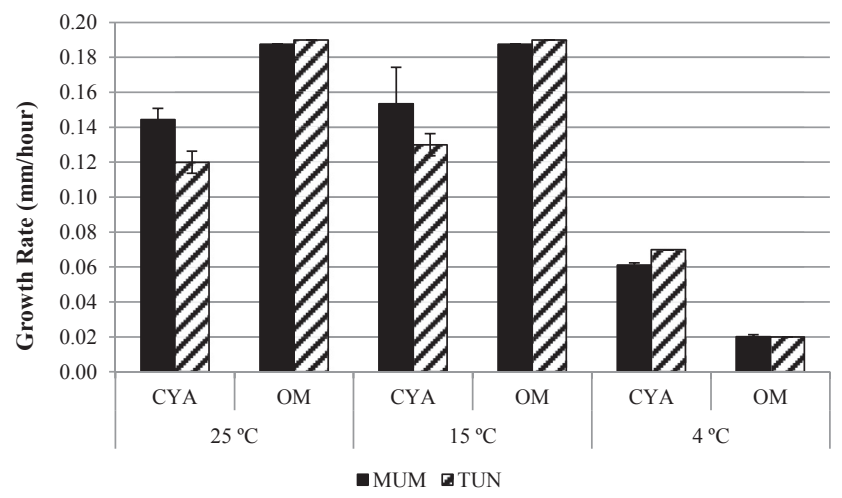

Fig. 2. Growth (mm/day) of MUM and TUN strains at $4{ }^{\circ} \mathrm{C}, 15^{\circ} \mathrm{C}$ and $25^{\circ} \mathrm{C}$, on CYA and OM.
CYA for $25^{\circ} \mathrm{C}$ and $15^{\circ} \mathrm{C}$ until the 10th d (Fig. 1 ), but between 10 and $20 \mathrm{~d}$ of incubation growth trend suffered an inflection, and fungi started to grow faster on OM. When analyzing growth at the end of incubation, this parameter was generally significantly higher ( $\mathrm{p}<0.05$ ) on OM for both fungi.

Interestingly, the strains displayed very different colony morphologies on the two media (Fig. 3). On CYA, growth was abundant (Fig. 3A-C), whereas on OM growth was poor on mycelium and was mostly based on highly spread (hence the colony diameter) and strongly sporulating synnemata (Fig. 3D-F), i.e. large, erect reproductive structures bearing compact conidiophores, which fuse together to form a strand with conidia at the end. The atypical growth on OM is probably a stress response to the less nutritive and more complex medium, while optimal growth conditions are offered by CYA.

At $4{ }^{\circ} \mathrm{C}$, growth followed a similar trend throughout time on both media, but with a growth significantly higher on CYA than on OM ( $p<0.05)$ for MUM and TUN strains. Growth rate of TUN was not significantly higher than that of MUM on both CYA $(p=0.25)$ and on OM $(\mathrm{p}=0.508)$.

Several studies have reported the growth conditions of P. expansum on fruit-based media, usually on apple or apple-based media. However, to our knowledge, this is the first study considering the growth of this fungus on olives and olive-based matrices. Radial growth of $P$. expansum growing at $25{ }^{\circ} \mathrm{C}$ in $\mathrm{OM}$ was $0.190 \mathrm{~mm} \mathrm{~h}^{-1}$, comparable to that reported on apples by Lahlali et al. (2005; $0.160 \mathrm{~mm} \mathrm{~h}^{-1}$ ), for the same temperature, but lower than that reported by Baert et al. (2007a; between 0.340 and $0.212 \mathrm{~mm} \mathrm{~h}^{-1}$ ) and Marín et al. (2006; $0.396 \mathrm{~mm} \mathrm{~h}^{-1}$ ). The lag time reported on apples by Baert et al. (2007a) was of 1 and $10 \mathrm{~d}$ at $25^{\circ} \mathrm{C}$ and $4{ }^{\circ} \mathrm{C}$, respectively. In our study, growth on $\mathrm{OM}$ for the same temperatures was observed at 1 and $9 \mathrm{~d}$ of incubation, respectively. This might indicate that, independently of the temperature, olives are not necessarily an inadequate matrix for $P$. expansum, as suggested for other fungi.

In fact, several studies have devoted to growth of other fungi on olives. Leontopoulos et al. (2003) studied the growth of Aspergillus parasiticus on intact black olives, and concluded that olives are not adequate for the growth of this aflatoxigenic fungus. However, previous reports (Mahjoub and Bullerman, 1987; Eltem, 1996) had indicated that damaged olives exhibited fast and extensive mycelial growth. It is probable that the outer pellicle of olives impedes fungal growth, and that olives are only open to fungal growth if injured. It must be noted that olives intended for oil extraction tend to be stored under inadequate conditions for long periods, and usually become highly injured and unprotected against fungal development.

The effect of temperature on fungal growth was performed at $4{ }^{\circ} \mathrm{C}, 15^{\circ} \mathrm{C}$ and $25^{\circ} \mathrm{C}$ for both media. These temperature conditions intend to reflect adequate conditions $\left(4{ }^{\circ} \mathrm{C}\right.$; refrigerated) and abusive storage conditions $\left(15^{\circ} \mathrm{C}\right.$ and $25^{\circ} \mathrm{C}$; plastic or jute bags piled outdoors) to which olives can be submitted during the storage period.

All the investigated strains of $P$. expansum were able to grow in the studied temperature range. Growth on CYA at the end of incubation was higher (but not significantly; $\mathrm{p}=0.822$ ) at $15^{\circ} \mathrm{C}$ than at $25{ }^{\circ} \mathrm{C}$ for both MUM and TUN strains, being that MUM grew significantly faster than TUN at $25^{\circ} \mathrm{C}(\mathrm{p}=0.019)$, but not at $15^{\circ} \mathrm{C}$ $(\mathrm{p}=0.073)$. Growth on OM was maximum for both temperatures, with $9 \mathrm{~cm}$ being achieved at the end of incubation. On the other hand, growth at $4{ }^{\circ} \mathrm{C}$ was significantly reduced when compared with higher temperatures $(\mathrm{p}=0.037)$. However, growth was not constant throughout this period. In general, the optimal growth temperature for MUM and TUN strains was $25^{\circ} \mathrm{C}$, at which the fungus exhibited the faster initial growth and the most significant 

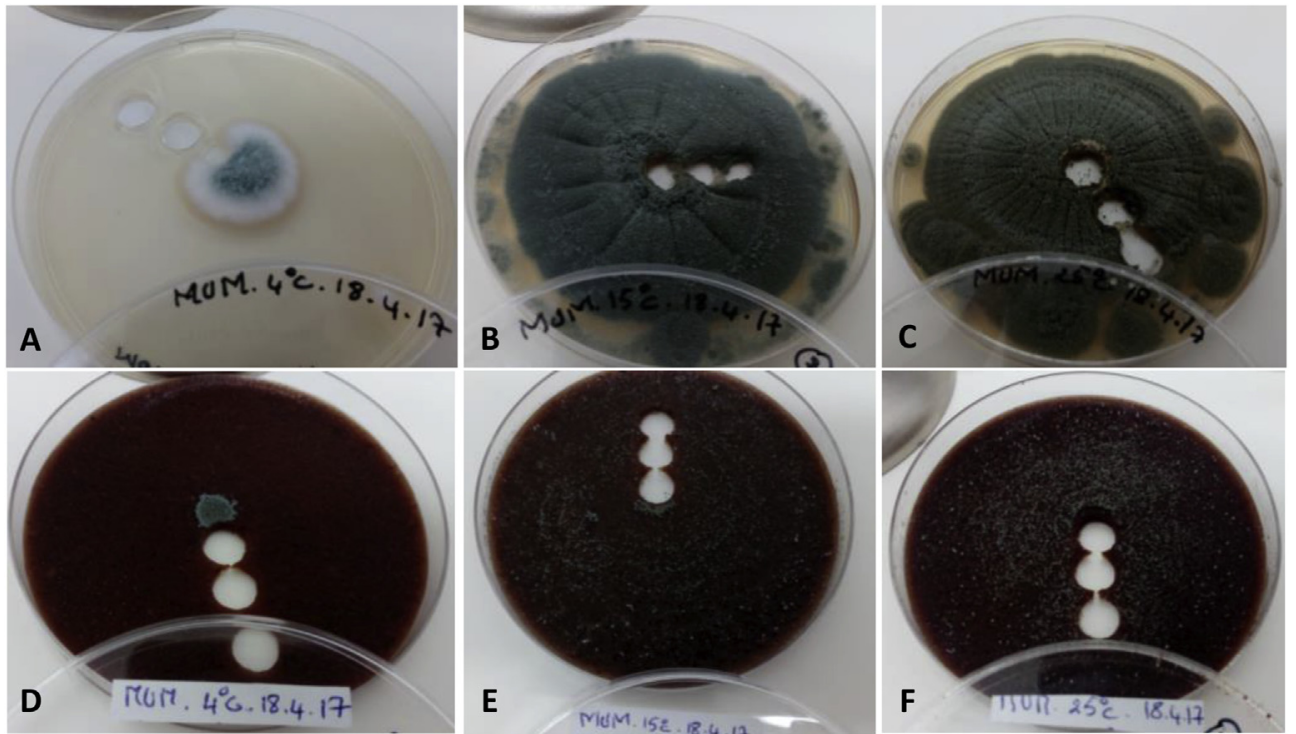

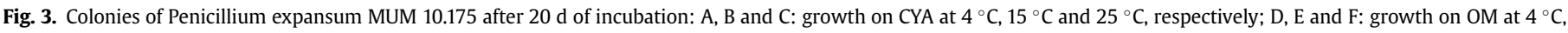
$15^{\circ} \mathrm{C}$ and $25^{\circ} \mathrm{C}$, respectively.

colony growth. The exception goes to growth of TUN strains, which was higher at $15^{\circ} \mathrm{C}$ on CYA than at $25^{\circ} \mathrm{C}$ on OM. This difference was, however, not significant $(p>0.05)$. The observation of optimal growth temperature is in accordance with that of other studies which describe also an optimum growth temperature for this species between $15{ }^{\circ} \mathrm{C}$ and $25{ }^{\circ} \mathrm{C}$ (Lahlali et al., 2005; Baert et al., 2007b; Pitt and Hocking, 2009; Tannous et al., 2016).

At $4{ }^{\circ} \mathrm{C}$, growth was only observed after $5 \mathrm{~d}$ (on CYA) or $10 \mathrm{~d}$ (on $\mathrm{OM}$ ) for both MUM and TUN fungi. A lag phase of $6 \mathrm{~d}$ was reported by Tannous et al. (2016) at $4{ }^{\circ} \mathrm{C}$ on CYA, with this period being reduced with increased temperatures. This result supports the conclusion of Baert et al. (2007a) that cold storage does not prevent fruit deterioration by $P$. expansum, just delays it. Also, although decay proceeds slowly at cold storage temperatures, rapid development occurs when the fruit is transferred to a warm environment (Fallik et al., 2001).

P. expansum is a psychrotrophic: optimal growth temperatures range from $15{ }^{\circ} \mathrm{C}$ to $25^{\circ} \mathrm{C}$, but minimum temperatures for growth have been reported between -2 and $-6{ }^{\circ} \mathrm{C}$, with growth still quite strong at $0{ }^{\circ} \mathrm{C}$ (Pitt and Hocking, 2009). P. expansum grew better at $25{ }^{\circ} \mathrm{C}$ than at $4{ }^{\circ} \mathrm{C}$ in $\mathrm{OM}$, although with longer incubation periods under refrigerated conditions, fungal growth could eventually catch up and result in significant contamination of olives.

Our results lead to the assumption that olives are adequate for $P$. expansum growth, and that olive matrix can be a limiting factor for fungal spread on olives only when low temperatures are maintained throughout storage. At abusive temperatures, $P$. expansum seems to induce a stress response and increase sporulation and dissemination, leading to potentially increased contamination by the fungus.

Table 1

Calibration parameters for patulin detection and quantification.

\begin{tabular}{ll}
\hline Parameter & Patulin \\
\hline $\mathrm{R}_{t}($ retention time $)$ & 7.2 \\
Calibration curve & $\mathrm{y}=4 \mathrm{E}-06 \mathrm{x}+0.9422$ \\
Correlation coefficient $\left(R^{2}\right)$ & 0.9994 \\
Linearity range $(\mu \mathrm{g} / \mathrm{mL})$ & 0.2 to 125 \\
LOD $(\mu \mathrm{g} / \mathrm{mL})$ & 4.5 \\
LOQ $(\mu \mathrm{g} / \mathrm{mL})$ & 12.9 \\
\hline
\end{tabular}

\subsection{Influence of matrix and temperature on patulin production}

The calibration parameters including equations of the linear regression, correlation coefficient $\left(\mathrm{R}^{2}\right)$, LOD and LOQ for patulin are shown in Table 1.

The recovery rate for each of the two media was determined by spiking $1 \mathrm{~g}$ of CYA and OM medium with a known concentration of $50 \mu \mathrm{g} / \mathrm{g}$. The recovery rate and relative standard deviation (RSD) are presented in Table 2.

Patulin recovery from OM (93.7\%) is higher than from CYA ( $77.3 \%)$, but the RSD is also higher (21.4\%), meaning that extraction from OM can introduce more bias in the result than from CYA. Indeed, patulin recovery obtained in our study is within the range of that observed in other studies, for example $92.9 \%-100.5 \%$ from commercial baby foods from Turkey (Karakose et al., 2015), $74 \%-105 \%$ in apple juice produced in Turkey (Aktas et al., 2004) and $86.5 \%$ in various fruit juices marketed in Tunisia (Zouaoui et al., 2015).

Patulin concentration on each medium (CYA and OM) and each temperature $\left(4^{\circ} \mathrm{C}, 15{ }^{\circ} \mathrm{C}, 25{ }^{\circ} \mathrm{C}\right)$ is shown in Fig. 4. A significant difference in patulin production was generally observed between MUM and TUN fungi ( $p<0.033$ ) after $10 \mathrm{~d}$ of incubation. The amount of patulin after $20 \mathrm{~d}$ was significantly different between fungi at $25^{\circ} \mathrm{C}(\mathrm{p}=0.024)$, at $15^{\circ} \mathrm{C}$ on OM $(\mathrm{p}=0.033)$ and at $4{ }^{\circ} \mathrm{C}$ on CYA $(\mathrm{p}=0.013)$, with TUN fungi producing higher amounts of patulin than MUM.

The differential production of patulin between MUM and TUN fungi might be due to the fact that the host of origin of the MUM strain was a contaminant of a $B$. cinerea culture (potentially originating from grapes) instead of olives. Sanzani et al. (2013) investigated the influence of the origin on $P$. expansum pathogenicity/ virulence and found that the $P$. expansum strains originating from a

Table 2

Recovery rate and relative standard deviation (RSD; $n=3$ ) of patulin on CYA and OM medium.

\begin{tabular}{lll}
\hline & Patulin $(50 \mu \mathrm{g} / \mathrm{g})$ & \\
\cline { 2 - 3 } & CYA & OM \\
\hline Recovery (\%) & 77.3 & 93.7 \\
RSD (\%) & 4.1 & 21.4 \\
\hline
\end{tabular}




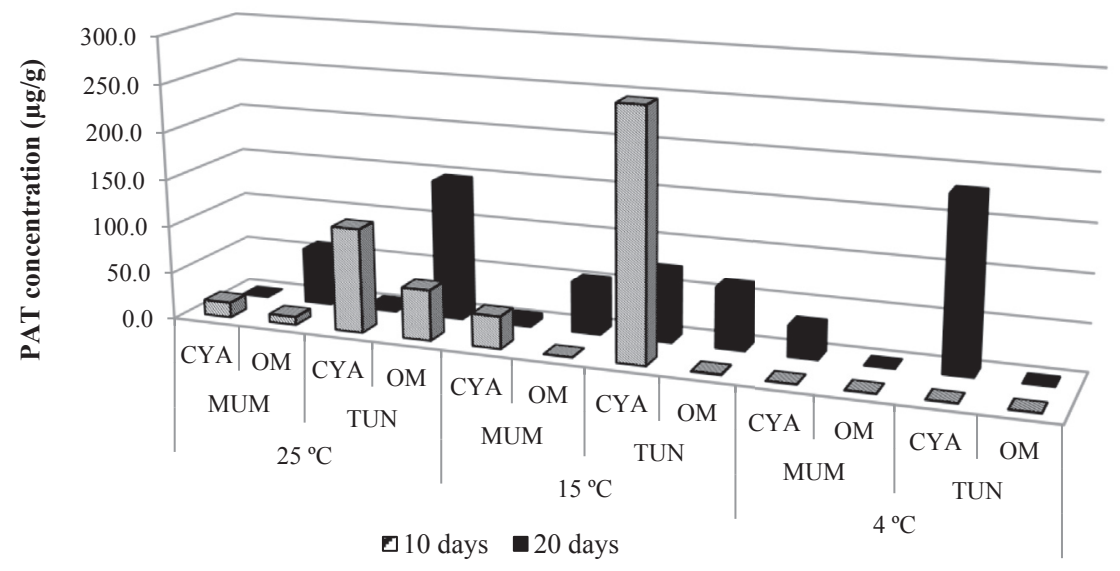

Fig. 4. Patulin production by MUM and TUN fungi at $25^{\circ} \mathrm{C}, 15^{\circ} \mathrm{C}$ and $4{ }^{\circ} \mathrm{C}$ after 10 and $20 \mathrm{~d}$ of incubation on CYA and OM.

given matrix produced more patulin in that host than strains originating from other hosts.

A weak correlation between fungal origin and patulin production on OM and CYA was detected in our study after $10 \mathrm{~d}$ (Pearson correlation $=0.309 ; \mathrm{p}=0.008$ ) and after $20 \mathrm{~d}$ (Pearson correlation $=0.328 ; \mathrm{p}=0.005$ ) of incubation, but this correlation was not consistent, since in most cases the amount of patulin produced by TUN fungi was higher on CYA than on OM. De Clercq et al. (2016) found that patulin production was more dependent on the temperature/atmosphere conditions or strain than on strain's origin.

Patulin production by $P$. expansum MUM and TUN exhibited a marked temperature- and matrix-dependent variability. The highest amount of patulin detected corresponded to TUN fungi growing on CYA, at $15{ }^{\circ} \mathrm{C}$, after $10 \mathrm{~d}$ of incubation. In fact, after this period patulin was always produced at higher amounts on CYA than on OM (significantly different for $15{ }^{\circ} \mathrm{C}$ and $25{ }^{\circ} \mathrm{C}$; p $<0.05$ ), regardless of the fungus, except at $4{ }^{\circ} \mathrm{C}$, where patulin was not detected. However, after $20 \mathrm{~d}$ of incubation, patulin was detected at significantly higher amounts on OM than on CYA at $25^{\circ} \mathrm{C}$ for both fungi and at $15^{\circ} \mathrm{C}$ for MUM ( $\mathrm{p}<0.033$ ). The amount of patulin was similar on both media at $15{ }^{\circ} \mathrm{C}$ for TUN fungi. At $4{ }^{\circ} \mathrm{C}$, patulin amounts increased significantly from 10 to $20 \mathrm{~d}$, and were significantly higher on CYA than on OM ( $p<0.037)$. In fact, fungi were unable to produce detectable amounts of patulin at $4{ }^{\circ} \mathrm{C}$ on the olive-based matrix.

Our results match those of other studies, including that of Baert et al. (2007b), where patulin production was reduced when the temperature decreased from 20 to 10 or $4{ }^{\circ} \mathrm{C}$. Also it was reported by Tannous et al. (2016) that the highest patulin concentrations were attained at around $16-17{ }^{\circ} \mathrm{C}$. In a study of patulin production by $P$. expansum in apple puree medium, De Clercq et al. (2016) indicated that low temperatures $\left(4^{\circ} \mathrm{C}\right)$ caused a delay of fungal metabolite production, but not its total inhibition.

Our results show two interesting aspects. One is that temperature, time of incubation and matrix affect significantly the ability of fungi to produce patulin. After $10 \mathrm{~d}$ of incubation, more patulin was detected on CYA than on OM, but an inflection of this trend was observed when the longer incubation period was analyzed. For $20 \mathrm{~d}$ of incubation, patulin was generally found in higher amounts on $\mathrm{OM}$, except at $4^{\circ} \mathrm{C}$. Even though fungi were able to produce patulin on CYA at $4{ }^{\circ} \mathrm{C}$, no patulin was produced on OM. Considering our results, refrigeration throughout storage seems to be safe for olives, at least for a storage period of up to $20 \mathrm{~d}$. On the contrary, storage temperatures of $15{ }^{\circ} \mathrm{C}$ and $25{ }^{\circ} \mathrm{C}$ are abusive conditions for long periods of storage. On this respect, fungi seem to have a long lag phase of patulin production on OM, but once this phase is overcome, high amounts of patulin are produced. Other authors have also reported that the length of time apples are stored at ambient temperature $\left(20^{\circ} \mathrm{C}\right)$ is critical for patulin accumulation (Morales et al., 2007c; Welke et al., 2011; Baert et al., 2012).

The other interesting aspect of these results is that amounts of patulin suffered a significant reduction from the 10th to 20th $d$ of incubation on CYA at $25^{\circ} \mathrm{C}$ and $15^{\circ} \mathrm{C}(\mathrm{p}<0.05)$. This effect was not observed at $4{ }^{\circ} \mathrm{C}$ and also not on $\mathrm{OM}$ at any temperature. Although this could be interpreted as a procedural error, this outcome was observed consistently in all fungi and in all replicas tested. The mechanism behind degradation of PAT and other mycotoxins has been reported by others, but is not well understood. Suggestions have been made that reduction in PAT contamination can be due to metabolic destruction caused by the fungus itself (Sommer et al., 1974). Furthermore, this metabolite decrease has been detected in olive matrices for other mycotoxins. It has been reported by Ghitakou et al. (2006) that the amount of aflatoxin B1 detected in black olives (produced by $A$. parasiticus) decreased after $9 \mathrm{~d}$ at $30^{\circ} \mathrm{C}$. In a study by Leontopoulos et al. (2003), aflatoxin B1 produced by A. parasiticus increased significantly after the 12 th $\mathrm{d}$ of incubation, while on olives incubated at $20{ }^{\circ} \mathrm{C}$ the toxin suffered a massive decrease after the same period of incubation. Citrinin amounts also decreased after $40 \mathrm{~d}$ of incubation at temperatures ranging from 20 to $30^{\circ} \mathrm{C}$ on black table olives (Heperkan et al., 2009).

It must be noted that these studies have occurred using pure cultures of the mycotoxigenic fungi, so mycotoxin degradation by competing microorganisms should not be considered. To our knowledge, no studies on mycotoxin degradation by the selfproducing fungi have been developed, and for that reason no explanation to this occurrence is available.

\section{Conclusions}

In conclusion, contamination of olives with patulin must be considered a potential risk in the safety and quality plans of the olive producing chain. The olive-based matrix seems to be adequate for growth and patulin production by $P$. expansum at storage abusive temperatures, so adequate temperatures throughout storage (refrigeration) are required to guarantee the safety of the product. If there is an abuse on storage temperature and longevity, patulin can turn into a real risk.

To our knowledge, this is the first report on the risk of $P$. expansum growth and patulin production on olives and 
olive-based products. More studies are needed to reinforce the results obtained in the present study.

\section{Acknowledgments}

The authors are grateful to the Foundation for Science and Technology (FCT, Portugal) and FEDER under Programme PT2020 for financial support to CIMO (UID/AGR/00690/2019).

\section{References}

Abdelhamid, S., Grati-kamoun, N., Marra, F., Caruso, T., 2013. Genetic similarity among Tunisian cultivated olive estimated through SSR markers. Sci. Agric. 70 (1), 33-38.

Abramson, D., Lombaert, G., Clear, R.M., Sholberg, P., Trelka, R., Rosin, E., 2009. Production of patulin and citrinin by Penicillium expansum from British Columbia (Canada) apples. Mycotoxin Res. 25 (2), 85-88.

Aktas, A.H., Yilmazer, M., Demerci, S., 2004. Determination of patulin in apple juice produced in Isparta, Turkey by HPLC with diode array detection. J. Food Drug Anal. 12 (3), 228-231.

Al-Ameiri, N.S., Karajeh, M.R., Qaraleh, S.Y., 2015. Molds associated with olive fruits infested with olive fruit fly (Bactrocera oleae) and their effects on oil quality. Jordan J. Biol. Sci. 8 (3), 217-220.

Andersen, B., Smedsgaard, J., Frisvad, J.C., 2004. Penicillium expansum: consisten production of patulin, chaetoglobosins, and other secondary metabolites in culture and their natural occurrence in fruit products. J. Agric. Food Chem. 52 (8), 2421-2428.

AOAC, 2000. Patulin in clear and cloudy apple juices and apple puree, liquid chromatographic method. AOAC official method 200.02. J. AOAC Int. 83, 1387.

Arici, M., 2000. Patulin production of Penicillium isolates from fermented olives in a synthetic medium. Ernaehrung 24 (6), 257-259.

Baert, K., Valero, A., De Meulenaer, B., Samapundo, S., Ahmed, M.M., Bo, L., Devlieghere, F., 2007a. Modeling the effect of temperature on the growth rate and lag phase of Penicillium expansum in apples. Int. J. Food Microbiol. 118 (2), $139-150$

Baert, K., Devlieghere, F., Flyps, H., Oosterlinck, M., Ahmed, M.M., Rajković, A., De Meulenaer, B., 2007b. Influence of storage conditions of apples on growth and patulin production by Penicillium expansum. Int. J. Food Microbiol. 119 (3), $170-181$.

Baert, K., Devlieghere, F., Amiri, A., De Meulenaer, B., 2012. Evaluation of strategies for reducing patulin contamination of apple juice using a farm to fork risk assessment model. Int. J. Food Microbiol. 154 (3), 119-129.

Bavaro, S.L., Susca, A., Frisvad, J., Tufariello, M., Chytiri, A., Perrone, G., Mita, G., Logrieco, A.F., Bleve, G., 2017. Isolation, characterization, and selection of molds associated to fermented black table olives. Front. Microbiol. 8, 1356, 14 pp.

Bragulat, M.R., Abarca, M.L., Cabañes, F.J., 2001. An easy screening method for fung producing ochratoxin A in pure culture. Int. J. Food Microbiol. 71 (2), 139-144.

De Clercq, N., Vlaemynck, G., Van Pamel, E., Van Weyenberg, S., Herman, L. Devlieghere, F., Van Coillie, E., 2016. Isoepoxydon dehydrogenase (idh) gene expression in relation to patulin production by Penicillium expansum under different temperature and atmosphere. Int. J. Food Microbiol. 220, 50-57.

EC, 20 December 2006. Commission Regulation (EU) No 1881/2006 of 19 December 2006 setting maximum levels for certain contaminants in foodstuffs. Off. J. Eur. Union. L364/5-24.

El Adlouni, C., Tozlovanu, M., Naman, F., Faid, M., Pfohl-Leszkowicz, A., 2006. Preliminary data on the presence of mycotoxins (ochratoxin A, citrinin and aflatoxin B1) in black table olives "Greek style" of Moroccan origin. Mol. Nutr. Food Res. 50 (6), 507-512.

Eltem, R., 1996. Growth and aflatoxin B1 production on olives and olive paste by moulds isolated from 'Turkish-style'natural black olives in brine. Int. J. Food Microbiol. 32 (1-2), 217-223.

Fallik, E., Tuvia-Alaklai, S., Copel, A., Wiseblum, A., Regev, R., 2001. A short hot water rinse and brushes: a technology to reduce postharvest losses -4 years of research. In: Ben-Arie, R., Philosoph-Hadas, S. (Eds.), Proceedings of the 4th International Conference on Postharvest, vol. 553. Acta Horticulturae, pp. $413-416$

Filtenborg, O., Frisvad, J.C., Thrane, U., 1996. Moulds in food spoilage. Int. J. Food Microbiol. 33 (1), 85-102.

Frisvad, J.C., Samson, R.A., 2004. Polyphasic taxonomy of Penicillium subgenus Penicillium. A guide to identification of food and air-borne terverticillate Penicillia and their mycotoxins. Stud. Mycol. 49 (1), 1-168.

Gardes, M., Bruns, T.D., 1993. ITS primers with enhanced specificity for basidiomycetes-application to the identification of mycorrhizae and rusts. Mol. Ecol. 2 (2), 113-118.

Gharbi, I., Issaoui, M., Mehri, S., Hammami, M., 2015. Quality Assurance of Tunisian oil mills. Qual. Food Saf. 21 (2), D202.

Ghitakou, S., Koutras, K., Kanellou, E., Markaki, P., 2006. Study of aflatoxin B1 and ochratoxin A production by natural microflora and Aspergillus parasiticus in black and green olives of Greek origin. Food Microbiol. 23 (7), 612-621.
Gil-Serna, J., Vazquez, C., Sandino, F.G., Valle, A.M., González-Jaén, M.T., Patiño, B., 2014. Evaluation of growth and ochratoxin A production by Aspergillus steynii and Aspergillus westerdijkiae in green-coffee based medium under different environmental conditions. Food Res. Int. 61, 127-131.

Gimeno, A., Martins, M.L., 1983. Rapid thin layer chromatographic determination of patulin, citrinin, and aflatoxin in apples and pears, and their juices and jams. J. Assoc. Off. Anal. Chem. 66 (1), 85-91.

Heperkan, D., Meric, B., Sismanoglu, G., Dalkiliç, G., Güler, F., 2006. Mycobiota, mycotoxigenic fungi, and citrinin production in black olives. In: Hocking, A.D., Pitt, J.I., Samson, R.A., Thrane, U. (Eds.), Advances in Food Mycology, pp. 203-210. Section 3: Physiology and Ecology of Mycotoxigenic Fungi.

Heperkan, D., Dazkır, G.S., Kansu, D.Z., Güler, F., 2009. Influence of temperature on citrinin accumulation by Penicillium citrinum and Penicillium verrucosum in black table olives. Toxin Rev. 28 (2-3), 180-186.

Heperkan, D., 2013. Microbiota of table olive fermentations and criteria of selection for their use as starters. Front. Microbiol. 4, 143. https://doi.org/10.3389/ fmicb.2013.00143.

Karakose, A., Sanli, S., Sanli, N., Bulduk, I., 2015. Evaluation of patulin in commercial baby foods by solid phase extraction and liquid chromatography PDA detection. Czech J. Food Sci. 33 (1), 52-57.

Lahlali, R., Serrhini, M.N., Jijakli, M.H., 2005. Studying and modelling the combined effect of temperature and water activity on the growth rate of $P$. expansum. Int. J. Food Microbiol. 103 (3), 315-322.

Laidou, I.A., Thanassoulopoulos, C.C., Liakopoulou-Kyriakides, M., 2001. Diffusion of patulin in the flesh of pears inoculated with four post-harvest pathogens. J. Phytopathol. 149 (7-8), 457-461.

Leggott, N.L., Shephard, G.S., 2001. Patulin in South African commercial apple products. Food Control 12 (2), 73-76.

Leontopoulos, D., Siafaka, A., Markaki, P., 2003. Black olives as substrate for Aspergillus parasiticus growth and aflatoxin B1 production. Food Microbiol. 20 (1), 119-126.

Mahjoub, A., Bullerman, L.B., 1987. Mold growth and aflatoxin production on whole olives and olive pastes. Sci. Aliment. 7 (4), 629-636.

Marín, S., Morales, H., Ramos, A.J., Sanchis, V., 2006. Evaluation of growth quantification methods for modelling the growth of Penicillium expansum in an applebased medium. J. Sci. Food Agric. 86 (10), 1468-1474.

Martins, M.L., Gimeno, A. Martins, H.M., Bernardo, F., 2002. Co-occurrence of patulin and citrinin in Portuguese apples with rotten spots. Food Addit. Contam. 19 (6), 568-574.

Morales, H., Marín, S., Centelles, X., Ramos, A.J., Sanchis, V., 2007a. Cold and ambient deck storage prior to processing as a critical control point for patulin accumulation. Int. J. Food Microbiol. 116 (2), 260-265.

Morales, H., Marín, S., Rovira, A., Ramos, A.J., Sanchis, V., 2007b. Patulin accumulation in apples by Penicillium expansum during postharvest stages. Lett. Appl. Microbiol. 44 (1), 30-35.

Morales, H., Sanchis, V., Rovira, A., Ramos, A.J., Marín, S., 2007c. Patulin accumulation in apples during postharvest: effect of controlled atmosphere storage and fungicide treatments. Food Control 18 (11), 1443-1448.

Morales, H., Marín, S., Obea, L., Patiño, B., Doménech, M., Ramos, A.J., Sanchis, V., 2008. Ecophysiological characterization of Penicillium expansum population in Lleida (Spain). Int. J. Food Microbiol. 122 (3), 243-252.

Morales, H., Marín, S., Ramos, A.J., Sanchis, V., 2010. Influence of post-harvest technologies applied during cold storage of apples in Penicillium expansum growth and patulin accumulation: a review. Food Control 21 (7), 953-962.

ONH, 2015. National Office of Oil. http://www.onh.com.tn/index.php/fr/ commercialisation/positionnement-sur-le-marche-mondial.

Pardo, E., Ramos, A.J. Sanchis, V., Marín, S., 2005. Modelling of effects of water activity and temperature on germination and growth of ochratoxigenic isolates of Aspergillus ochraceus on a green coffee-based medium. Int. J. Food Microbiol. 98 (1), 1-9.

Pitt, J.I. Hocking, A.D., 2009. Fungi and Food Spoilage, 3 ed. Springer, United States.

Puel, O., Galtier, P., Oswald, I.P., 2010. Biosynthesis and toxicological effects of patulin. Toxins 2 (4), 613-631.

Rodrigues, P., Venâncio, A., Kozakiewicz, Z., Lima, N., 2009. A polyphasic approach to the identification of aflatoxigenic and non-aflatoxigenic strains of Aspergillus section Flavi isolated from Portuguese almonds. Int. J. Food Microbiol. 129 (2), 187-193.

Rodrigues, P. Santos, C. Venâncio, A., Lima, N., 2011. Species identification of Aspergillus section Flavi isolates from Portuguese almonds using phenotypic, including MALDI-TOF ICMS, and molecular approaches. J. Appl. Microbiol. 111, $877-892$.

Rodrigues, P., Venâncio, A., Lima, N., 2013. Incidence and diversity of the fungal genera Aspergillus and Penicillium in Portuguese almonds and chestnuts. Eur. J. Plant. Pathol. 137 (1), 197-209.

Rodríguez, A. Capela, D., Medina, Á., Córdoba, J.J., Magan, N., 2015. Relationship between ecophysiological factors, growth and ochratoxin A contamination of dry-cured sausage based matrices. Int. J. Food Microbiol. 194, 71-77.

Roussos, S., Zaouia, N., Salih, G., Tantaoui-Elaraki, A., Lamrani, K., Cheheb, M. Ismaili-Alaoui, M., 2006. Characterization of filamentous fungi isolated from Moroccan olive and olive cake: toxinogenic potential of Aspergillus strains. Mol. Nutr. Food Res. 50 (6), 500-506.

Samson, R.A., Hoekstra, E.S., Frisvad, J.C., 2004. Introduction to Food-And Airborne Fungi. CBS, Utrecht, The Netherlands. 
Sanderson, P.G., Spotts, R.A., 1995. Postharvest decay of winter pear and apple fruit caused by species of Penicillium. Phytopathology 85 (1), 103-110.

Sanzani, S.M., Montemurro, C., Di Rienzo, V., Solfrizzo, M., Ippolito, A., 2013. Genetic structure and natural variation associated with host of origin in Penicillium expansum strains causing blue mould. Int. J. Food Microbiol. 165 (2), 111-120.

Sommer, N.F., Buchanan, J.R., Fortlage, R.J., 1974. Production of patulin by Penicillium expansum. Appl. Microbiol. 28 (4), 589-593.

Tannous, J., Atoui, A., El Khoury, A., Francis, Z., Oswald, I.P., Puel, O., Lteif, R., 2016. A study on the physicochemical parameters for Penicillium expansum growth and patulin production: effect of temperature, $\mathrm{pH}$, and water activity. Food Sci. Nutr. 4 (4), 611-622.

Taverniers, I., De Loose, M., Van Bockstaele, E., 2004. Trends in quality in the analytical laboratory. II. Analytical method validation and quality assurance. Trends Anal. Chem. 23 (8), 535-552.
Vipotnik, Z., Rodríguez, A., Rodrigues, P., 2017. Aspergillus westerdijkiae as a major ochratoxin A risk in dry-cured ham based-media. Int. J. Food Microbiol. 241, 244-251.

Welke, J.E., Hoeltz, M., Dottori, H.A., Noll, I.B., 2011. Patulin accumulation in apples during storage by Penicillium expansum and Penicillium griseofulvum strains. Braz. J. Microbiol. 42 (1), 172-180.

White, T.J., Bruns, T., Lee, S.J.W.T., Taylor, J.W., 1990. Amplification and direct sequencing of fungal ribosomal RNA genes for phylogenetics. In: Innis, M.A. Gelfald, D.H., Sninsky, J.J., White, T.J. (Eds.), PCR Protocols: a Guide to Methods and Applications, vol. 18. Academic Press, New York, USA, pp. 315-322.

Zouaoui, N., Sbaii, N., Bacha, H., Abid-Essefi, S., 2015. Occurrence of patulin in various fruit juice marketed in Tunisia. Food Control 51, 356-360. 